\title{
SCHALEN VAN SURINAAMSCHE PALM- EN ANDERE BOOMZADEN VOOR DE BEREIDING VAN GAS-ADSORPTIEKOOL ${ }^{1}$ )
}

\author{
DOOR
}

IR. W. SPOON

Van de k l a p p e r- of cocosnoot, de vrucht van de cocospalm, Cocos nucifera LINN., is bekend, dat zij een steenschaal bevat, die een goede grondstof is voor de bereiding van gas-adsorptiekool. De doppen of schalen zijn bijproduct van de copra-winning, zij dienen, ter besparing op de vracht, ter plaatse te worden verkoold, waarna in Europa de activeering van de kool en afwerking op bepaalde korrelgrootte plaats vindt. Met die korrels worden o.a. de filterbussen van gasmaskers gevuld.

Sinds omstreeks 1930 zijn de klappercentra Ceylon, Celebes en Java in Oost-Indië en Jamaica in West-Indië in toenemende mate verkoolde klapperdoppen naar Europa gaan uitvoeren ${ }^{2}$ ). Dat was mogelijk, doordat de cocospalm in zoovele gebieden door de bevolking in cultuur is genomen en dus de vruchten en daarmede de doppen regelmatig ter beschikking komen. Hetzelfde zien wij ook bij de oliepalm Elaeis guineensis JACQ., die in het bijzonder op Sumatra en Malakka intensief in cultuur is gebracht. De steenschalen uit de vruchten van deze palm zijn een der afvalproducten van de oliepalm-onderneming, die ten deele als brandstof dienen, doch waarvan enkele jaren geleden op instigatie van de Afdeeling Handelsmuseum van het Koloniaal Instituut aan-

1) Tevens Bericht van de Afdeeling Handelsmuseum van het Koloniaal Instituut No. 186.

2) Verg. W. Spoon ,,Verkoolde plantaardige materialen uit Nederlandsch-Indië en de bereiding van actieve kool", Ber. Afd. Handelsmuseum I07, ook verschenen in Ind. Mercuur 59, 475 (1936) en Bergcultures IO (II), 1027 (1936), voorts ,Inlichtingen en Onderzoekingen v/d Afd. Handelsmuseum in 1936", blz. 92 en idem 1939 blz. 76 (Meded. Afd. Handelsmuseum ${ }_{7} 7$ en 21 ).

$$
-257-
$$

West-Indische Gids XXIV 
getoond kon worden, dat zij evenals de klapperdop een uitstekende grondstof voor actieve kool vormen 1).

De in de Zuid- en Midden-Amerika voorkomende palmsoorten zijn daar vrijwel niet in cultuur genomen, zoodat men voor het verkrijgen van de vruchten op inzameling in het bosch is aangewezen. Locaal gebruikt de bevolking wel het vet aanwezig in de kernen en/of het vruchtvleesch, maar op een enkele uitzondering na is het nergens tot een export van eenige beteekenis dier kernen gekomen. Zij dienen daarenboven nog gekraakt te worden, want niet de steenschaal, maar de vethoudende kern vormt het doel van een export. In tegenstelling met de cocosnoot en de oliepalmvrucht is dan ook van het meerendeel der Zuid-Amerikaansche palmvruchten nog niet nagegaan, of de daarin aanwezige steenschaal voor de vervaardiging van actieve kool (d.w.z. voor gasbinding, want voor ontkleuringsdoeleinden is naar de inzichten van de betrokken industrie een schalenkool in het algemeen ongeschikt) waarde heeft. Toch kan het bij de winning van kernen om geldelijke redenen van beteekenis zijn te weten, of het afvalproduct steenschaal toepassing zou kunnen vinden. Wij hebben daarom een onderzoek in die richting verricht.

Bij de keuze van het materiaal hebben wij in het bijzonder gelet op Suriname, waar vertegenwoordigers van een aantal vethoudende palmengeslachten inheemsch zijn. Wij hebben dan ook getracht in de eerste plaats daarvan materiaal te verkrijgen. J. SACK noemt in zijn boek ,Plantaardige voortbrengselen van Suriname" 2) de daar voorkomende palmsoorten, waarvan de voornaamste zijn de a w a r r a, Astrocaryum segregatum DRUDE, en de mari pa, Maximiliana Maripa (MART.) DRUDE (verg. fig. 1). Gedroogde vruchten of noten waren in de verzamelingen van het Koloniaal Instituut in voor het onderzoek voldoende hoeveelheid aanwezig. Ook van de door SAck beschreven pa r a mak ka, Astrocaryum Paramaca MART. waren noten beschikbaar, echter niet van de k a u m a k k a, Acrocomia sclerocarpa MART.; in de plaats daarvan beschikten wij over een monster, dat er vermoedelijk zeer nabij kwam en dat wij destijds onder den naam „Patagonia nuts uit Zuid-Amerika" hadden ontvangen. Hij noemt verder de cocospalm en de oliepalm, doch die zijn in Suriname

1) W. Spoon ,,Palmkerndoppen”, Ber. Afd. Handelsmuseum I42, ook verschenen in Ind. Mercuur 63, 11 (1940) en Bergcultures I3 (II), 1764 (1939).

2) Bull. Depart. Landbouw Suriname 23 (1910). 
niet inheemsch maar ingevoerd, terwijl daarenboven van de steenschaal van de vruchten dier palmen de waarde als grondstof voor actieve kool reeds bekend is. Dat speciaal de cocospalm in het district Coronie geregeld aangeplant wordt, kan in dit verband voor Suriname van beteekenis zijn.

Van buiten Suriname hadden wij in de verzamelingen b a b a s s u-noten van de palm Orbignya Martiana BARB. RODR. (syn. Attalea funifera MART.) uit Brazilië. De noten worden in het bosch verzameld en de steenschalen ter plaatse verwijderd, waarna de vethoudende kernen of pitten in hoofdzaak naar Noord-Amerika worden uitgevoerd ${ }^{\mathbf{1}}$ ). De grootste moeilijkheid vormt het kraken van de zeer harde schalen.

Jammer genoeg beschikten wij niet over voldoende vruchten van de cohun e, Attalea cohune Mart. syn. Orbignya cohune (MART.) Dahlgren ${ }^{2}$ ) en de c o y o l, Acrocomia vinifera Oerst., omdat van die vruchten in de literatuur gebruik van de steenschaal voor koolbereiding wordt beschreven.

De cohune-palm komt voor in Centraal-Amerika en daarvan in het bijzonder in Britsch-Honduras ${ }^{3}$ ). Tijdens den oorlog van 1914-'18 is komen vast te staan, dat uit de steenschaal van de vruchten van deze palm een goede gas-adsorptiekool vervaardigd kan worden $\left.{ }^{4}\right)$. Voordien was reeds bekend, dat de kernen een uitstekend spijsvet bevatten. De Vereenigde Staten van Amerika hebben in de zooeven genoemde jaren de inzameling van zaden georganiseerd, waarbij zij in de eerste plaats afnemers van de steenschaal zijn geweest. Het bijeenbrengen der zaden is echter niet eenvoudig, terwijl het kraken van de harde schalen zonder de vethoudende kernen te beschadigen al evenmin medevalt, zoodat na 1918 de belangstelling voor de cohune-noten sterk verminderd is.

De coyol- of cayolpalm komt eveneens in Centraal-Amerika voor, in het bijzonder in de staat Veracruz van de Mexicaansche republiek. Reeds in de tweede druk van zijn leerboek over warenkennis en technologie (1927) deelt J. F. vaN Oss op blz. 736 mede, dat uit de steenschalen van de coyolvruchten (en die van de cohune-vruchten) een

$\left.{ }^{1}\right)$ C. v. D. Koppel „,De babassu-palm en zijn vethoudend zaad”, Ber. Afd. Handelsmuseum I68 (1941).

2) P. C. Standley ,'The Cohune palm an Orbignya, not an Attalea”, Trop. Woods 30,1 (1932).

3) Zie b.v. de beschrijving van J. Sibinga Mulder in Tijdschr. Econ. Geografie 6, 249 (1915) en van N. S. Stevenson in Trop. Woods 30,3 (1932).

4) J. Temminck Groll ,Vetleverende palmen uit de geslachten Attalea en Maximiliana", Ber. Afd. Handelsmuseum 2, ook verschenen in Ind. Mercuur 43, 175, 193 en 207 (1920); verg. verder J. H. BURKILL "A Dictionary of the economic products of the Malay Peninsula", 267 (1935). 
prima actieve kool is te bereiden. Volgens recente berichten 1) is in Amerika een matschappij opgericht om in Veracruz de vruchten te verzamelen en te verwerken op olie uit het vruchtvleesch, de kernen op vet en perskoek; als bijzonderheid wordt er aan toegevoegd, dat uit de steenschalen actieve kool verkregen kan worden.

Aangezien Suriname naast vethoudende palmzaden ook vethoudende zaden van andere boomen kent, met name in de eerste plaats de s a wa r i e-noot van Caryocar nuciferum Linn. ${ }^{2}$ ) (verg. fig. 2) en de p a r a-noot van Bertholletia excelsa H.B.K. ${ }^{3}$, verder de $\mathrm{k} \mathrm{r}$ a p p a - pit van Carapa guyanensis AuBL., hebben wij de schalen daarvan tevens in het onderzoek betrokken. Eerstgenoemde worden met het oog op hun gebruik als tafelnoten in toenemende mate gepeld uitgevoerd, hetgeen reeds in Brazilië voor de para-noot tot een gecentraliseerde bewerking (vooral te Belém) heeft geleid. Tenslotte hebben wij nog de schaal van $\mathrm{k}$ a $\mathrm{n}$ a r i-zaden (van den boom Canarium commune LiNN.) van Java in het onderzoek opgenomen, waarvan de vethoudende kern eveneens als versnapering wordt gegeten ${ }^{4}$ ).

In tabel I zijn enkele bijzonderhẹden van de onderzochte zaden bijeengebracht.

In het bijzonder bij de palmzaden blijkt de schaal wat gewicht aangaat verre in de meerderheid tegenover de vethoudende kern.

Een punt, dat verder speciaal de aandacht vraagt, is de dikte van de schaal. De verkoolde schalen moeten - zooals in den aanvang reeds vermeld - na activeering worden afgewerkt tot korrels. Indien bestemd voor gasmaskers, zijn die korrels in verband met de ademweerstand aan de minimum diameter van $1^{3} / 4$ à $2 \mathrm{~mm}$ gebonden; reeds bij de onderzoekingen met klapperdoppen was dan ook door de industrie als minimum dikte der verkoolde schalen 2 à $2^{1} / 2 \mathrm{~mm}$ voorgeschreven. Zooals wij straks nog nader zullen zien, krimpen bij de verkoling de schalen iets.

1) Chem. Ind. N. 64, 657 (1941).

2) G. Stahel ,De sawarie-noot en enkele andere in Suriname in het wild groeiende noten", Serie overdrukken Landbouwproefstation 7 , ook verschenen in Ind. Mercuur 58, 689 (1935).

W. Spoon „Sawarie-noten uit Suriname”, Ber. Afd. Handelsmuseum $I 09$, ook verschenen in Ind. Mercuur 6o, 1 (1937).

3) C. v. D. KOPPEL „Para-noten, sapucaia- en piquia-noten uit het Amazone-gebied", Ber. Afd. Handelsmuseum 180 , ook verschenen in Oliën, Vetten, Oliezaden $26,339,355$ en 373 (1941/42).

4) Verg. b.v. K. HEYNE ,De nuttige planten van NederlandschIndië", deel II 1927, 875. 


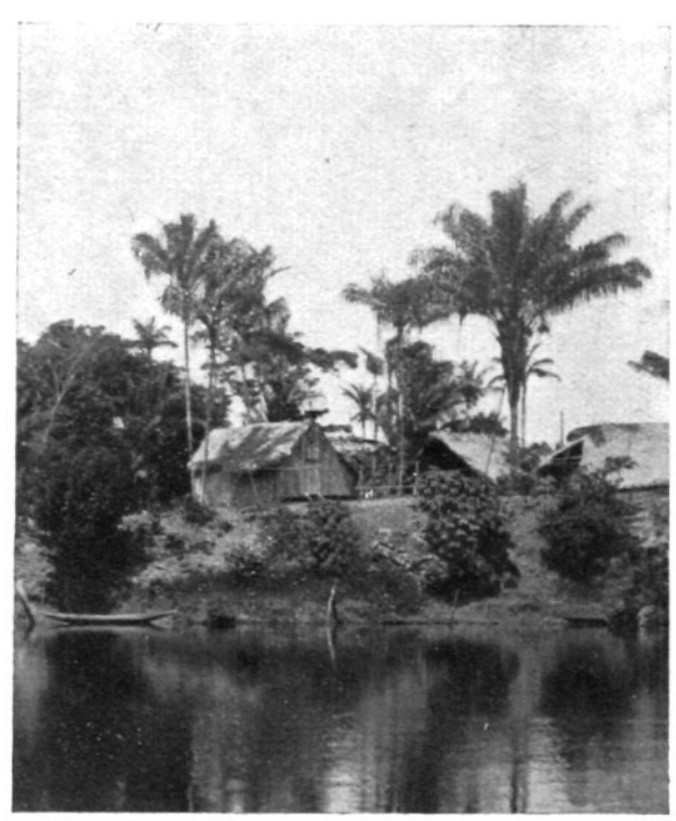

Coll. Kol. Inst., opn. J. W. Gonggrijp.

Fig. 1. Links awarra-palmen, rechts maripapalmen bij een Indianendorp aan de Wajambo, Suriname. 
W. SPOON, PALM- EN ANDERE BOOMZADEN

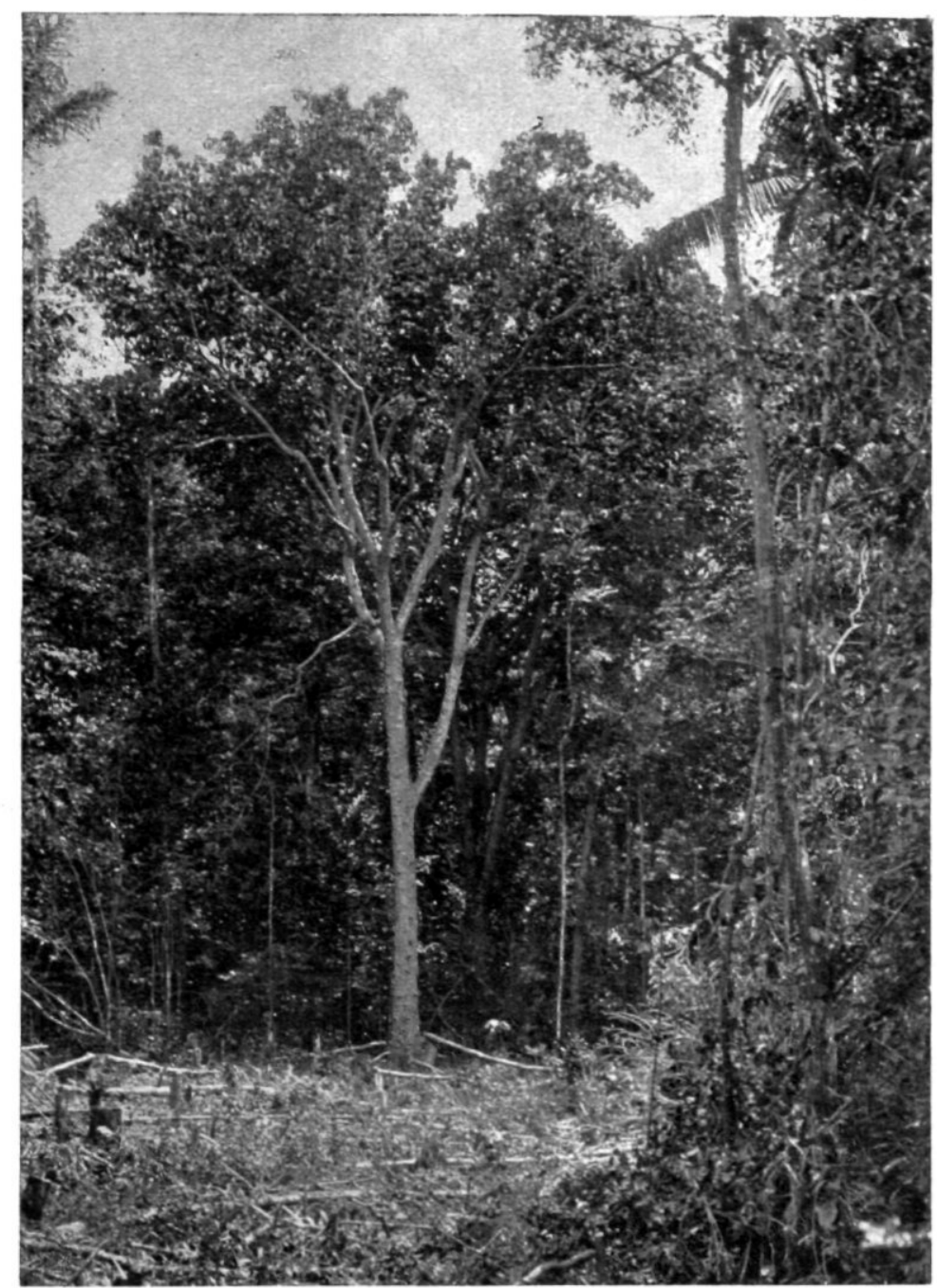

Coll. Kol. Inst., opn. G. Stahel (cliché bruikleen J. H. de Bussy)

Fig. 2. Sawarie-boom in het bosch aan de Kaboerie-kreek (Corantijn), Suriname. 
TABEL I.

IN HET ONDERZOEK BETROKKEN ZADEN

\begin{tabular}{|c|c|c|c|c|c|c|}
\hline Monster No. & $\begin{array}{l}\text { locale naam } \\
\text { en herkomst }\end{array}$ & botanische naam & gew. zaad & gew. kern & gew. schaal & dikte schaal \\
\hline 244 & $\begin{array}{l}\text { awarra, } \\
\text { Suriname }\end{array}$ & $\begin{array}{l}\text { Astrocaryum } \\
\text { segregatum DRUDE }\end{array}$ & $10 \mathrm{~g}$ & $3 g$ & $7 \mathrm{~g}$ & $\pm 3 \mathrm{~mm}$ \\
\hline K.M. 3423-7 & $\begin{array}{l}\text { maripa, } \\
\text { Suriname }\end{array}$ & $\begin{array}{l}\text { Maximiliana } \\
\text { Maripa (MART.) DRUDE }\end{array}$ & $\pm 12 \mathrm{~g}$ & $<2 g$ & $>10 \mathrm{~g}$ & $3.5-4.5 \mathrm{~mm}$ \\
\hline $59-2$ & $\begin{array}{l}\text { paramakka, } \\
\text { Suriname }\end{array}$ & $\begin{array}{l}\text { Astrocaryum } \\
\text { Paramaca MART. }\end{array}$ & $\pm 4 \mathrm{~g}$ & $1.5 \mathrm{~g}$ & $>2 \mathrm{~g}$ & $1.5-1.7 \mathrm{~mm}$ \\
\hline 640 & $\begin{array}{l}\text { Patagonia } \\
\text { nut, Zuid- } \\
\text { Amerika }\end{array}$ & $\begin{array}{l}\text { Acrocomia spec. verm. } \\
\text { A. sclerocarpa MART. }\end{array}$ & $\pm 8 \mathrm{~g}$ & $<2 \mathrm{~g}$ & $>6 \mathrm{~g}$ & $3-4 \mathrm{~mm}$ \\
\hline 1625 & $\begin{array}{l}\text { babassu, } \\
\text { Brazilië }\end{array}$ & $\begin{array}{l}\text { Orbignya Martiana } \\
\text { BARB. RODR. }\end{array}$ & $\pm 57 \mathrm{~g}$ & $6 \mathrm{~g}$ & $51 \mathrm{~g}$ & $6-9 \mathrm{~mm}$ \\
\hline 1899 & idem & idem & & verkoold & ontvangen & \\
\hline 3104 & $\begin{array}{l}\text { sawarie, } \\
\text { Suriname }\end{array}$ & $\begin{array}{l}\text { Caryocar } \\
\text { muciferum LINN. }\end{array}$ & $60 \mathrm{~g}$ & $\pm 12 \mathrm{~g}$ & $\pm 48 \mathrm{~g}$ & $6-10 \mathrm{~mm}$ \\
\hline 3784 & $\begin{array}{l}\text { para-noot, } \\
\text { Brazilië }\end{array}$ & $\begin{array}{l}\text { Bertholletia } \\
\text { excelsa H.B.K. }\end{array}$ & $7 \mathrm{~g}$ & $3.5 \mathrm{~g}$ & $3.5 \mathrm{~g}$ & $\begin{array}{l}1.5-2 \mathrm{~mm} \text {, } \\
\text { ribben 4-5 }\end{array}$ \\
\hline K.M. 1350-8 & $\begin{array}{l}\text { krappa, } \\
\text { Suriname }\end{array}$ & $\begin{array}{l}\text { Carapa } \\
\text { guyanensis AUBL. }\end{array}$ & $8-9 \mathrm{~g}$ & $6 \mathrm{~g}$ & $2.5 \mathrm{~g}$ & $1.2 \mathrm{~mm}$ \\
\hline K.M. 3550 & $\begin{array}{l}\text { kanari, } \\
\text { Java }\end{array}$ & $\begin{array}{l}\text { Canarium } \\
\text { commune LINN. }\end{array}$ & $7.5 \mathrm{~g}$ & $1 .-\mathrm{g}$ & $6.5 \mathrm{~g}$ & $3.4 \mathrm{~mm}$ \\
\hline
\end{tabular}


Daarmede rekening houdende, zien wij uit tabel I, dat bij de vrucht van de paramakka en bij de krappa-pit de schaal te dun, bij de para-noot ten deele beneden, ten deele boven de grens is (hiervan is namelijk de vorm driekantig met dunne vlakken maar dikke ribben). De schalen van de paramakka en de krappa zijn daarom niet verder onderzocht, die van de para-noot wel.

Wij hebben de diverse schalen verkoold in een klein-model plaatijzeren retort, waarvan de verhitting ongeveer een uur tot circa $450^{\circ} \mathrm{C}$ werd voortgezet. Hoe de schalen er vervolgens uitzagen, leert ons tabel II.

Uit tabel II blijkt, dat de opbrengst aan kool ongeveer een derde deel van het gewicht der schalen bedraagt, hetgeen met de ervaring bij klapperdoppen en oliepalmschalen overeenkomt. Inderdaad zijn verder de schalen bij de verkoling iets gekrompen. Het karakter van de verkregen kool is echter verschillend; er zijn verkoolde schalen, die hard aanvoelen, niet bros zijn en waarmede dan ook op papier slechts een flauwe streep is te verkrijgen, tegenover zachte en broze schalen, die op papier een breede streep achterlaten. Met de herkomst uit palm- of andere boomzaden houdt dit verschil geen verband. Dergelijke na verkoling zachte en broze schalen zullen gemakkelijk vergruizen en dus moeilijk te vervoeren zijn, terwijl nog te bezien staat in hoeverre er goede korrels uit zijn te verkrijgen; een en ander geldt in het bijzonder voor de kool van de Patagonia-nut en die van de sawarie-noot.

Het beste, wat de hardheid aangaat, is de kool van maripa en babassu. Trouwens, in Brazilië is reeds eerder de verkoling van de babassu-schalen beproefd en afzet voor de kool gezocht 1). Zoo ontving de Afdeeling Handelsmuseum in 1931 een dergelijke zending (No. 1899) uit Maranhao; het gelukte toen echter niet afzet voor de kool te vinden.

Ook Suriname zou t.z.t. de schalen van zijn palm- en verdere boomzaden zelf moeten verkolen. Moeilijk is die bewerking niet, doch wel dienen er enkele regels bij in acht te worden genomen, opgemaakt aan de hand van de ervaring bij de verkoling van klapperdoppen opgedaan. $\mathrm{Zij}$ komen neer op een zoo volledig mogelijke verkoling, terwijl de kool niet nat mag zijn, vrij moet zijn van zand en aarde en zoo min mogelijk vergruisd. Fabrikanten wenschen namelijk in verband met de beschreven korreling, de kool zooveel mogelijk als stukken (schaalfragmenten), waarbij

1) Ber. Afd. Handelsmuseum $I 68,8$. 
TABEL II.

RESULTAAT VAN DE VERKOLING

\begin{tabular}{|c|c|c|c|c|c|c|c|c|c|}
\hline \multirow[b]{2}{*}{ Monster No. } & \multirow[b]{2}{*}{ locale naam } & \multirow{2}{*}{$\begin{array}{l}\text { rende- } \\
\text { ment }\end{array}$} & \multicolumn{2}{|c|}{ dikte schaal } & \multirow{2}{*}{$\begin{array}{l}\operatorname{aard} \mathrm{v} / \mathrm{d} \\
\text { kool }\end{array}$} & \multirow{2}{*}{$\begin{array}{l}\text { teekening } \\
\text { op papier }\end{array}$} & \multicolumn{3}{|c|}{ samenstelling $\mathrm{v} / \mathrm{d}$ kool } \\
\hline & & & $\begin{array}{c}\text { vóór } \\
\text { verkoling }\end{array}$ & $\begin{array}{c}\mathrm{na} \\
\text { verkoling }\end{array}$ & & & $\begin{array}{l}\text { vocht } \\
\%\end{array}$ & $\begin{array}{c}\text { asch } \\
\%\end{array}$ & $\begin{array}{c}\text { vluchtig } \\
\%\end{array}$ \\
\hline 244 & awarra & $32 \%$ & $\pm 3 \mathrm{~mm}$ & $2.5 \mathrm{~mm}$ & $\begin{array}{l}\text { hard, } \\
\text { tamelijk } \\
\text { bros }\end{array}$ & $\begin{array}{l}\text { tamelijk } \\
\text { dun }\end{array}$ & 2.0 & 3.0 & 16.0 \\
\hline K.M. 3423-7 & maripa & $31 \%$ & $3.5-4.5 \mathrm{~mm}$ & $3.7 \mathrm{~mm}$ & $\begin{array}{l}\text { hard, } \\
\text { niet bros }\end{array}$ & $\begin{array}{l}\text { zeer } \\
\text { dun }\end{array}$ & 1.1 & 3.7 & 16.1 \\
\hline 640 & Patagonia nut & $30 \%$ & $3-4 \mathrm{~mm}$ & $4.2 \mathrm{~mm}$ & $\begin{array}{l}\text { zacht, } \\
\text { zeer bros }\end{array}$ & dik & 3.2 & 7.2 & 14.6 \\
\hline 1625 & babassu & $30 \%$ & $6-9 \mathrm{~mm}$ & - & - & - & 2.8 & 4.6 & 20.7 \\
\hline 1899 & ", & - & - & $4.7 \mathrm{~mm}$ & $\begin{array}{l}\text { hard, } \\
\text { niet bros }\end{array}$ & $\begin{array}{l}\text { zeer } \\
\text { dun }\end{array}$ & 5.7 & 5.3 & 7.7 \\
\hline 3104 & sawarie & $36 \%$ & $6-10 \mathrm{~mm}$ & $16.4 \mathrm{~mm}$ & $\begin{array}{l}\text { zacht, } \\
\text { zeer bros }\end{array}$ & dik & 1.8 & 0.8 & 21.8 \\
\hline 3784 & para-noot & $38 \%$ & $\begin{array}{l}1.5-2 \text {, } \\
\text { ribben }\end{array}$ & $\begin{array}{l}1,4 \\
\text { ribben }\end{array}$ & $\begin{array}{l}\text { hard, } \\
\text { tamelijk }\end{array}$ & dun & 3.3 & 2.3 & 19.7 \\
\hline K.M. 3550 & kanari & $33 \%$ & $\begin{array}{l}4-0 \mathrm{~mm} \\
3.4 \mathrm{~mm}\end{array}$ & $3.0 \mathrm{~mm}$ & $\begin{array}{l}\text { Dros } \\
\text { hard, } \\
\text { tamelijk } \\
\text { bros }\end{array}$ & dun & 2.7 & 4.1 & 16.4 \\
\hline
\end{tabular}


gruis geen waarde heeft. Tenslotte verlangen de scheepvaartmaatschappijen, wegens het gevaar van doorstuiven en daarmede verontreiniging van andere lading, bij gebruik van jute-emballage verpakking van de verkoolde schalen in dubbele zakken. Hier zou wellicht gebruik van de meerwandige papieren zak (fabrikaat Bates) een oplossing voor die moeilijkheid kunnen vormen.

Geheel nieuw zou dat niet zijn, want reeds in 1933 heeft op Java het Boschwezen voor de verzending van verkoold djati- en wildhout (in de eerste plaats kesambi-houtskool) naar de gebruikscentra papieren zakken gebezigd 1). Zoo'n zak kon $20 \mathrm{~kg}$ houtskool bevatten; de constructie was verder zoo eenvoudig mogelijk gehouden, namelijk 3-wandig, van het kruisbodemmodel, de naden waren geplakt. Aanvankelijk werden de zakken kant en klaar uit Europa betrokken, doch nadien in gevangenisarbeid vervaardigd uit geïmporteerd kraftpapier.

Voor export zouden de zakken steviger moeten zijn, b.v. 5-wandig, en niet geplakt doch genaaid. Suriname zou ze vermoedelijk het eenvoudigst rechtstreeks van een der fabrieken in Amerika kunnen betrekken.

Verontreiniging van de kool met zand, aarde e.d. kan uit het aschgehalte blijken. Het eigen aschgehalte van de schalen loopt echter, gezien de desbetreffende cijfers in tabel II, uiteen, zoodat een voor alle schaalsoorten bindend maximumgehalte aan aschbestanddeelen moeilijk te geven is. Wel voor elke soort afzonderlijk, zooals het b.v. tusschen Indië en Nederland voor verkoolde klapperdoppen al eenige jaren geleden vastgesteld is kunnen worden op $2.5 \%$ in de luchtdroge stof. De bij dat overleg vastgestelde grens voor het vochtgehalte van ten hoogste $10 \%$, zal vermoedelijk zonder bezwaar voor alle schaalsoorten in verkoolden vorm overgenomen kunnen worden.

Voor de beoordeeling van het adsorbeerend vermogen zijn twee wegen gevolgd, namelijk de binding van jodium en die van aetherdamp. In beide gevallen is de kool op dezelfde manier voorbehandeld; eerst gepoederd en gezeefd op B 20 (d.i. een zeef met een draadafstand of maasopening van $0.3 \mathrm{~mm}$ ), waarna een deel zoo is onderzocht, de rest na activeering met zinkchloride ${ }^{2}$ ). Ter vergelijking zijn eenige monsters klapperdoppenkool en palmkerndoppenkool mede onderzocht.

De adsorptie van jodium is als volgt gedaan: $0.5 \mathrm{~g}$ kool wordt 5 uur geschud in een thermostaat bij $25^{\circ} \mathrm{C}$ met $50 \mathrm{~cm}^{3} 0.05 \mathrm{~nJ}$-oplossing,

1) Tectona 26, 990 (1933) en 32, 686 (1939).

2) Methode v/h Rijks-Instituut voor Brandstoffen-Economie 's-Gravenhage, waarbij de met een $5 \%$ opl. van $\mathrm{ZnCl}_{2}$ gedrenkte kool 4 uur wordt gegloeid op $600^{\circ} \mathrm{C}$, vervolgens uitgewasschen en gedroogd. 
na snel filtreeren wordt het filtraat teruggetitreerd met $0.05 \mathrm{n}$ natriumthiosulfaat; de uitkomst wordt berekend als mg-aequivalenten jodium vastgelegd per één gram kool.

De adsorptie van aetherdamp is verricht volgens de methode die A. J. van DuURen, chem. drs., in ons laboratorium heeft uitgewerkt voor bleekaarde ${ }^{1}$ ). Het adsorptie-vermogen van de te onderzoeken stof wordt daarbij volumetrisch bepaald, hetgeen tevens mogelijk maakt het beloop van de adsorptie met den tijd te vervolgen. Voor de beoordeeling van een koolsoort, die bestemd is voor de binding van gassen, is dat zeer belangrijk. Naast de in tabel III bijeengebrachte eindcijfers van de adsorptie van jodium en aetherdamp, hebben wij daarom in een grafiek (z.o.z.) het beloop van de adsorptie van aetherdamp aan de diverse koolsoorten weergegeven, ons daarbij beperkend tot de kool in geactiveerden toestand, omdat die vorm de praktijk het meest nabij komt.

TABEL III.

ADSORPTIE-METINGEN.

\begin{tabular}{|c|c|c|c|c|c|}
\hline \multirow{2}{*}{ Monster No. } & \multirow{2}{*}{$\begin{array}{l}\text { verkoolde } \\
\text { dop van }\end{array}$} & \multicolumn{2}{|c|}{$\begin{array}{c}\text { jodium (mg aeq./g } \\
\text { kool) }\end{array}$} & \multicolumn{2}{|c|}{ aetherdamp (in \%) } \\
\hline & & $\begin{array}{c}\text { oorspron- } \\
\text { kelijk }\end{array}$ & $\begin{array}{l}\text { geacti- } \\
\text { veerd }\end{array}$ & $\begin{array}{l}\text { oorspron- } \\
\text { kelijk k }\end{array}$ & $\begin{array}{l}\text { geacti- } \\
\text { veerd }\end{array}$ \\
\hline 244 & awarra & 2.23 & 3.36 & - & 11.7 \\
\hline K.M. 3423-7 & maripa & 1.52 & 2.16 & 6.2 & 10.0 \\
\hline 640 & $\begin{array}{l}\text { Patagonia } \\
\text { nut }\end{array}$ & 1.86 & 2.76 & - & 9.7 \\
\hline 1899 & babassu & 1.10 & 2.94 & - & 8.0 \\
\hline 3104 & sawarie & 1.80 & 4.28 & $9.6^{5}$ & 13.3 \\
\hline 3784 & para-noot & 1.42 & 3.16 & - & 11.8 \\
\hline K.M. 3550 & kanari & 2.31 & 3.66 & 10.0 & 11.5 \\
\hline 2689 & klapper & 1.72 & 4.10 & - & 13.0 \\
\hline $3408-2$ & ," & 1.33 & 3.14 & 7.5 & 10.8 \\
\hline 4270 & & 1.25 & 3.83 & - & 12.6 \\
\hline 4151 & oliepalm & 0.41 & 3.43 & 3.6 & 12.2 \\
\hline 4457 & , & 0.60 & 3.51 & - & 13.1 \\
\hline
\end{tabular}

1) Proefschrift in bewerking. 


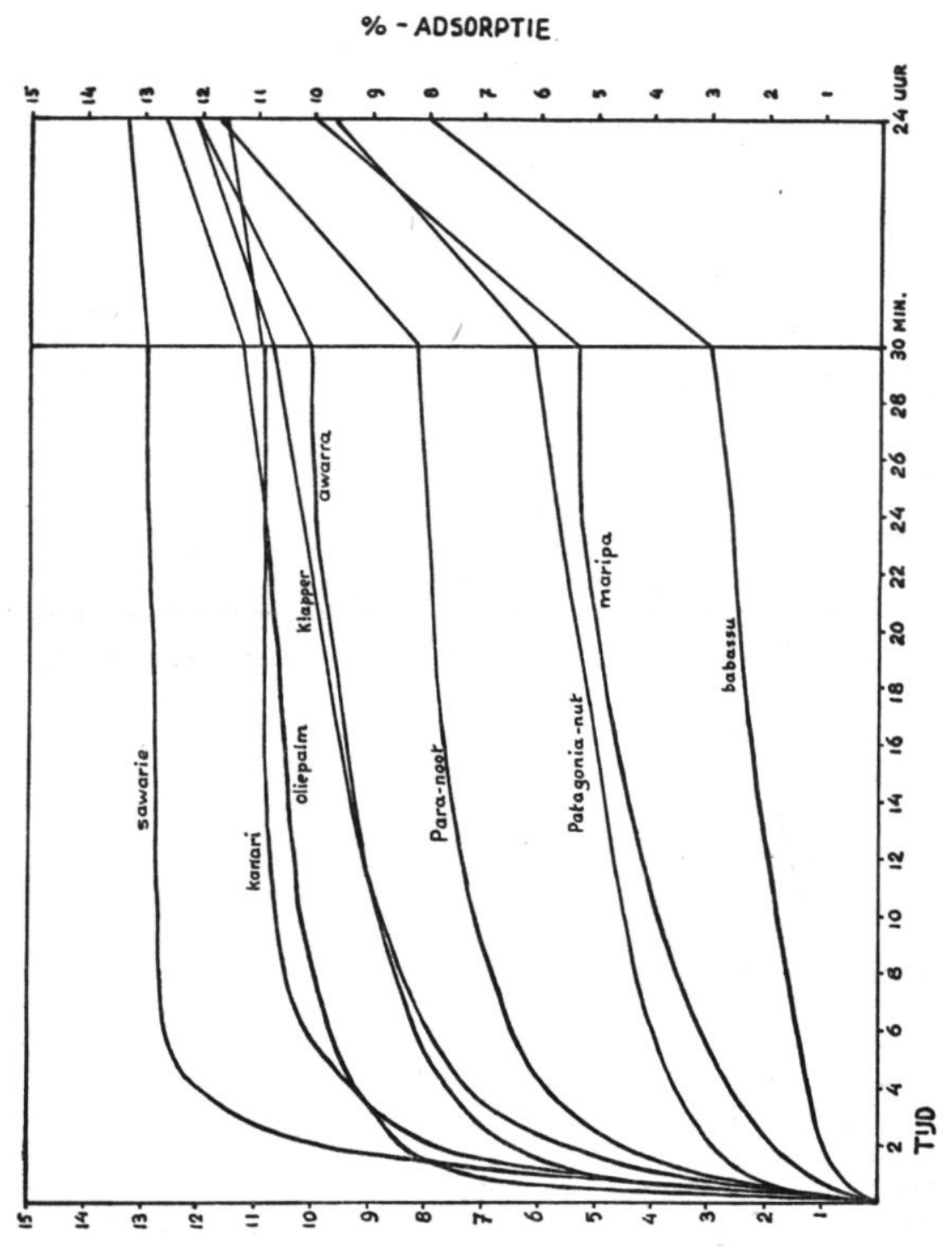

Beloop van de adsorptie van aetherdamp aan de verkoolde schalen

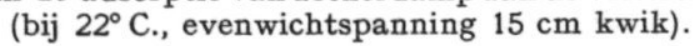


Uit tabel III blijkt, dat beide metingen parallel loopende uitkomsten geven; een kool, die na activeering behoorlijk jodium bindt, doet zulks ook voor aetherdamp. Het effect van de activeering kan daarbij soms verrassend groot wezen, zie b.v. de monsters palmkerndoppenkool.

Nemen wij de uitkomsten van de kool van klapperdop en palmkerndop in geactiveerden toestand als uitgangspunt, dan zien wij, dat van de overige palmzaden slechts die van de awarra daar dichtbij komen, bij de andere boomzaden maakt vooral sawarie een goede indruk. Een tegenvaller vormt de kool van babassuschalen; dat wij voor die kool destijds - d.w.z. in 1931 - geen belangstelling konden vinden, behoeft dus nu niet meer te verwonderen.

Wij hebben vervolgens over de laboratoriumresultaten nog overleg gepleegd met de industrie van gas-adsorptie- en andere koolpreparaten. Daarbij werd de schaal van de para-noot als geheel genomen toch te dun bevonden; wij hebben er trouwens al op gewezen, dat van deze schalen slechts de ribben aan de vereischte minimummaat zouden voldoen. Ook van de kanari-pit werd de schaal wat dikte betreft als op de grens zijnde beschouwd, wat gezien het resultaat der adsorptiemetingen jammer is. De sawarie-dop maakte een gunstigen indruk, al blijft de eigenaardige brosheid na verkoling nog een punt, dat misschien door de praktijk nader bezien zal moeten worden.

Hoe staat het nu met de mogelijkheden voor exploitatie van vethoudende palm- en boomzaden in Suriname? Besproken worden die o.a. in het rapport van het Suriname Studie-Syndicaat, dat door J. S. C. Kasteleyn, B. J. Kluvers en E. Snellen uitgebracht is over hun in 1919 ondernomen studiereis ${ }^{1)}$ (blz. 151 onder het hoofd „,Andere boschproducten”).

Maripa en awarra worden in de eerste plaats door hen genoemd, omdat die reeds verreweg de belangrijkste vetproducenten zijn voor de in het binnenland gevestigde boschnegers en indianen, zoodat het den rapporteurs mogelijk voorkomt, dat de zaden in een of anderen vorm een uitvoerartikel zullen worden. Vervolgens noemen zij de krappa-pitten, die misschien ook beteekenis voor de toekomst kunnen krijgen.

In aansluiting op die opmerkingen heeft ook TJ. PyTTERSEN ${ }^{2}$ ) nog eens de aandacht op maripa en awarra gevestigd, met moge-

1) Samenvatting in West-Ind. Gids $I, 287$ (1919/20).

2) West-Ind. Gids 2, $509(1920 / 21)$. 
lijkheid van uitvoer der kernen. Naderhand zijn van Fransche zijde beide palmen uitvoerig beschreven ${ }^{1}$ ), omdat men er ook in Cayenne economische beteekenis in zag.

In 1926 scheen een en ander voor Suriname tot resultaten te zullen leiden; opgericht werd namelijk door Amerikaansche belanghebbenden de Dutch Guiana Oil Extraction Company (N.V. Nederlandsch-Guyana Oliewinning Maatschappij) gevestigd te Paramaribo, waaraan gerekend van 1 Januari 1927, voor den tijd van 5 jaren, concessie werd verleend om ter bereiding van olie, zaden van krappa-boomen, van de verschillende palmsoorten en van andere boomen en planten te verzamelen op een perceel land, groot ongeveer 61.000 ha, oostelijk van den Corantijn 2 ).

$\mathrm{Na}$ een begin van uitvoering der werkzaamheden, in den vorm van een exploratie van het terrein en het zoeken naar de geschiktste vet-extractiemethode, is niets meer van deze maatschappij vernomen. Dus ook eenigerlei gegevens over de schalen dier zaden zijn uitgebleven.

Die zijn tenslotte wel tot op zekere hoogte verkregen bij de sawarie-noot, toen daarvan in 1936 tot pelling in Paramaribo werd overgegaan, zoodat slechts de kernen werden uitgevoerd, in navolging van hetgeen in Brazilië met de para-noot geschiedde (verg. litt. blz. 260). Voor de schalen is toen in Nederland belangstelling geweest als grondstof voor knoopenfabricage; zij bleken daartoe echter niet geschikt, doordat zij als gevolg van de manipulaties verbonden aan het winnen der kernen - drogen en kraken - te veel scheurtjes bevatten en te ongelijke stukken opleverden. Verkolingsproeven zijn destijds niet genomen; slechts weten wij dus, dat de schalen centraal beschikbaar zouden zijn.

Afgerond is het vraagstuk van de mogelijkheid van bijeenbrenging der schalen van awarra en sawarie dus nog geenszins, doch voor het oogenblik zullen andere tijden afgewacht moeten worden, alvorens over meer gegevens te kunnen beschikken.

Amsterdam, Juni 1942.

1) F. Heim DE BALSAC en medewerkers ,l'Aouara, palmier oléifère de Guyane” en „Le maripa, palmier oléifère de la Guyane Française”, Bull. Ag. Gén. Col. 19, 1180 (1926), 20, 73 (1927) en 24, 595 (1931).

2) „De economische toestand van Suriname in 1926", blz. 5 en idem 1927 blz. 5; Ind. Mercuur 5o, 107, 180 en 312 (1927). 